\title{
The Colonized and the Wrong of Colonialism
}

In "What's Wrong with Colonialism," Lea Ypi argues that the distinctive wrong of colonialism should be understood as the failure of the colonial relationship to extend equal and reciprocal terms of political association to the colonized. Laura Valentini argues that Ypi's account fails. Her argument targets an ambiguity in Ypi's account of the relata of the colonial relationship. Either Ypi's view is that the members of the colonized group are, as individuals, denied an equal and reciprocal political relationship to the colonizer, or Ypi's view is that the colonized individuals form a collective agent and that it is denied an equal and reciprocal relationship to the colonizer. According to Valentini, both options face insurmountable difficulties. This paper argues that Valentini sets up a false dilemma: the third option is to think of the colonizer as relating in an unequal and non-reciprocal way to the plurality of people subjected to colonial rule. This view, I argue, avoids Valentini's objections, but it also raises new questions about how we are to understand the distinctive wrong of colonialism.

\section{What's Wrong with Colonialism}

Ypi defines colonialism as "a practice that involves both the subjugation of one people to another and the political and economic control of a dependent territory (or parts of it)" (2013, 162). Ypi takes colonialism to be a relationship between political collectives. She assumes that we know what the relevant political collectives are, "that indigenous societies or tribal groups do count as political collectives," and that "individuals, family members, interest groups, or civil society associations" do not $(2013,162)$. I will use the colonial rule of Java by the Dutch government as a standard example. For the sake of 
simplicity, I will refer to the colonizer in this relationship as the Dutch, and to the colonized as the Javanese. ${ }^{1}$

Ypi's central claim is that the distinctive wrong of colonialism consists in the failure of the political association, established by the colonial relationship, to offer terms of equality and reciprocity to the colonized. This wrong has two components. The first is that the original creation of the colonial relationship fails to respect the norms of equality and reciprocity that apply to the establishment of political associations. The second component is that the rules and principles governing the colonial relationship, once it is established, fail to reflect the norms of equality and reciprocity that apply to the internal structure of political associations. Of course, colonial relationships are not the only political associations that violate norms of equality and reciprocity; apartheid and caste societies, for example, and societies that oppress minorities do so as well. The distinctive wrong of colonialism is the territorial manifestation of this generic wrong (2013, 163). Further, Ypi's account does not deny that, historically, colonialism is associated with a wide range of other wrongs-oppression, murder, genocide, torture, and so on-wrongs which, on Ypi's own view, "capture most of the wrong of colonialism" $(2013,162)$. These wrongs, however, are not distinctive of colonialism in

${ }^{1}$ This simplifies matters with regard to both the colonizer and the colonized. Various parts of Java were subject to colonial control and influence by the Dutch East India Company from the late 16th century onwards. After 1800, parts of Java came under Dutch governmental control, with Dutch victory in the Java War in 1830 marking the beginning of the truly colonial period in Javanese history (Ricklefs 2001, 155). Referring to the colonized on Java as "the Javanese" sweeps together about 7 million inhabitants in 1830, organized into the kingdoms of Yogyakarta and Surakarta, and including three main ethnic groups, the Javanese, the Sundanese, and the Madurese (Ricklefs 2001, chapters 11 and 12). 
the sense that these wrongs can and do occur outside of colonial relationships. Ypi's account aims to specify the distinctive wrong of colonialism in the sense that colonial relationships uniquely and necessarily instantiate this wrong. ${ }^{2}$

What do the ideals of equality and reciprocity require of the establishment and maintenance of a political association between territorially distinct political agents? Ypi only answers this question explicitly with regard to the establishment of new political associations, and she answers it initially in terms of consent: "for an associative offer to be considered effectively equal and reciprocal, the consent of those on the receiving end is required" (2013, 179). The relevance of consent is in turn explained in terms of sensitivity to the will of the associating parties: consent is required because it offers the best available proxy for the consenting agent's will (Ypi 2013, 180). Ypi does not discuss what equality and reciprocity require of the internal structure of political associations, but we can imagine that this might involve fair terms of economic cooperation and equal participation in political decision-making and the exercise of political power. For ease of exposition, I will speak of Ypi's view as claiming that colonialism is wrong because it involves the subjugation of the colonized.

\section{Valentini's Dilemma}

2 The sense in which colonialism is a distinctive wrong on Ypi's account is somewhat delicate.

The wrong involved in colonialism is the generic wrong of "morally objectionable political relations" (Ypi 2013, 163). Colonialism distinguishes itself from other manifestations of this generic wrong by being applied to territorially distinct political agents. "But, although

territoriality is descriptively crucial in distinguishing colonialism from other wrongs in the same family, it should not matter normatively" $(2013,162)$. 
Valentini's dilemma targets an ambiguity in Ypi's understanding of 'the colonized'. On the aggregative interpretation, we should understand 'the colonized' to refer to each of the members of the colonized group individually; on the corporate interpretation, 'the colonized' refers to a collective agent. On either interpretation, Valentini argues, the account fails. I should note at the outset that Valentini's discussion targets Ypi's consent condition; I will reformulate her argument in terms of subjugation. ${ }^{3}$

According to the aggregative interpretation, colonialism is wrong because it involves the subjugation of the individual members of the relevant political collective. Valentini's central objection to the aggregative interpretation is that it over-ascribes the family of wrongs to which colonialism belongs. She claims, first, that there are cases in which it is not wrong to subjugate particular individuals; for example, when such subjugation is necessary to keep the individual from seriously harming others (2015, 316-318). As a consequence, there could be political associations which subjugate some individuals but which are nonetheless rightful political associations. The aggregative conception, however, considers all such political associations to instantiate the wrong of colonialism, or a non-territorial cousin of this wrong. Furthermore, this over-ascription is illustrated by existing political associations: no political association succeeds in realising equal and reciprocal terms with, or in tracking the will of, each and every member $(2015,318)$. Unless we are willing to say that the family of wrongs to which colonialism belongs is ubiquitous-exemplified by today's British, Dutch, and Spanish political associations as well as by the colonial powers they once were $(2015,318)$-the aggregative interpretation fails to identify the distinctive wrong of colonialism.

3 This comes at a cost. I will use the term 'subjugation' as a term of art, referring to Ypi's overall account of the wrong of colonialism. The negative connotations of our everyday usage of the term 'subjugation' may make Valentini's argument seem less plausible than it is. 
On the corporate interpretation, colonialism is wrong because it involves the subjugation of a corporate agent constituted by the members of the relevant political collective. Valentini's argument against the corporate interpretation sets up another dilemma. Either, the corporate interpretation claims that corporate agents have a moral standing of their own, and that it wrongs the colonized, understood as a corporate agent, to be subjugated by the colonizer. In this case, Ypi's view is inconsistent with normative individualism - the idea that individual human beings, and not corporate agents, are the ultimate units of moral concern $(2015,324)$. Or, the corporate interpretation claims that the normative significance of the subjugation of corporate agents is explained in terms of the legitimate interests of the individual members. In this case, Ypi's view is consistent with normative individualism, but implausible. Since she claims that colonialism is always wrong, she would be committed to the view that individual members of a political collective always have a legitimate interest in the corporate agent that they constitute being free from subjugation. If the relevant corporate agent is a sufficiently tyrannical regime, however, and the prospective colonizer sufficiently benign, individual members may have a legitimate interest in colonial takeover, and no legitimate interest in the tyrannical regime being free from subjugation $(2015,324)$. Valentini concludes that on either construal, the corporate interpretation is mistaken. ${ }^{4}$

\section{The Colonized}

Valentini's dilemma is a false dilemma: we are not forced to interpret 'the colonized' as either the individual members of the colonized group, or as the corporate agent they

\footnotetext{
${ }^{4}$ My brief reconstruction here leaves out much of the detail in Valentini's discussion (2015, 316-326); however, my argument will not depend on the further details.
} 
constitute. The third option can be illustrated with a simple example. Suppose you are overlooking a schoolyard with 50 playing children in it. "Those children are loud," you may say. In saying this, you could mean to ascribe the property of being loud to some or all of the children individually. Alternatively, you could mean that the children constitute some complex object, a group perhaps—or an ingratitude or chaos—and that it is loud. These are not, however, our only two options: you could have meant that they are loud. You could have meant to ascribe the property of being loud to the plurality of children in the playground. ${ }^{5}$

To make this more explicit, consider your statement interpreted as predicating loudness of the children individually. In that case, your statement would be incorrect if none of the children, individually, is loud. More precisely, the statement "those children (individually) are loud" is true if and only if some, many, most, or all the children individually instantiate the property of being loud. ${ }^{6}$ Your claim that those children are loud could be true, however, even if none of the children are individually loud; each child's rather modest volume may combine with the others to result in a noisy playground. One way to capture this is to understand your claim as predicating loudness of a complex object, such as a group, constituted by the children. The statement "those childrenc (complex object) are loud" is true if and only if those children constitute a complex object and it is loud. But we could also understand your claim as predicating loudness of the plurality of children in the playground. They are loud, without any of them being loud individually, and without them constituting a further thing which is loud. A plurality of children can be loud by jointly realizing the

5 This paragraph and the next draw on discussions of plurals and shared agency in Smith 2011 and Mellor 2017.

${ }^{6}$ Whether the truth of the statement requires, at one extreme, only some children to be loud, or, at the other extreme, all of them will depend on a variety of factors. 
conditions of loudness. "Those childrenpL (plurally) are loud" if and only if the plurality of children in the playground jointly instantiate the property of being loud.7

We now have three ways to understand who the colonized are, and so three ways to understand the wrong of colonialism. This is best illustrated using the example of Dutch colonial rule on Java. The first understanding is as follows:

The Dutch subjugated the Javanese I

On this view, the distinctive wrong of colonialism was instantiated if and only if the Dutch subjugated some, many, most, or all of the Javanese individually. ${ }^{8}$ The second interpretation is:

The Dutch subjugated the Javanesec

The colonial rule of Java exemplified the distinctive wrong of colonialism, on this view, if and only if the Javanese constituted some complex object, a people perhaps, and the Dutch subjugated it. ${ }^{9}$ Third:

The Dutch subjugated the JavanesepL

On this interpretation, Ypi's view is that the Dutch rule of Java instantiated the wrong of colonialism if and only if the Dutch subjugated the relevant plurality of Javanese people. For this to have been the case, a plurality of Javanese persons must have jointly

${ }^{7}$ This relies on the availability of non-distributive plural quantification. It is not part of this essay to provide a defense of this. For a helpful overview of the literature on plural quantification, see Linnebo 2014.

${ }^{8}$ We can now see that Valentini's charge that the aggregative interpretation over-ascribes the wrong of colonialism is directed at a specific version of this view—the objection only works against views on which the individual subjugation of any or a few of the Javanese would have sufficed to instantiate the wrong of colonialism.

${ }^{9}$ Here again, Valentini's objections are addressed at a particular version of this view, where the relevant complex object is understood as a corporate agent. 
realized the conditions of being subjugated by the Dutch. We can generalize these three views beyond the example of the Javanese, so that we arrive at three different interpretations of the general wrong of colonialism: the distinctive wrong of colonialism is the subjugation of the colonized $\mathrm{I}_{\text {, the }}$ colonized $\mathrm{C}$, or the colonizedPL.

The plural interpretation of Ypi's view avoids Valentini's objections. The problem with the aggregative interpretation was that it led to an over-ascription of the family of wrongs to which the wrong of colonialism belongs. Every existing political association subjugates some of it members and, further, it is sometimes permissible to subjugate individuals. Nonetheless, the aggregative view holds that all such political associations instantiate a wrong like the wrong of colonialism. On the plural interpretation, this conclusion would only follow if the subjugation of one or more individual members of a political association suffices for the plurality of the members being jointly subjugated. It is quite implausible, however, that the subjugation of some Swedish individuals by the Swedish State, say, entails that the plurality of Swedish people are jointly subjugated by the Swedish State. This is true more generally: it does not follow from the fact that some of the children in the playground are individually loud that the plurality of children jointly are loud. Of course, this ultimately turns on what it takes for a plurality to jointly instantiate the property of being subjugated. I will return to that issue in section 4 .

Valentini's objection to the corporate interpretation came in the form of a dilemma. The first horn takes the corporate interpretation to claim that the relevant corporate agent is an "ultimate unit of moral concern" $(2015,324)$, such that the wrong of the subjugation of the corporate agent is understood independently of the legitimate interests of the individual members of the subjugated group. This, Valentini claims, is incompatible with normative individualism. This part of Valentini's criticism is difficult to respond to because she neither explains nor defends normative individualism. Could the joint subjugation of the plurality of Javanese people be morally significant 
independently of the legitimate interests of individual Javanese persons? I will simply register my relative lack of confidence in a negative answer compared to Valentini's.

The second horn construes the corporate interpretation in normatively individualist terms: the wrong of colonialism is the subjugation of a relevant corporate agent, but the normative significance of such subjugation is in turn explained in terms of the legitimate interests of the individual members. The problem here is that the only available corporate agent may be, for example, a tyrannical and unjust state. The corporate view now has to say that the subjugation of that tyrannical state is wrong because it conflicts with the legitimate interests of the individual members of the political collective. If the potential colonizer is sufficiently benevolent, however, then the individual members do not have a legitimate interest in the continued nonsubjugated existence of the tyrannical state $(2015,324)$. The plural interpretation does not lead to these difficulties. If the Javanese, before Dutch colonial rule, were governed by a tyrannical state, the plural interpretation does not say that the wrong of colonialism consists in the subjugation of the tyrannical state. Instead, it holds that the wrong of colonialism consists in the plurality of Javanese persons being jointly subjugated. ${ }^{10}$ The normatively individualist version of this view says that the wrong of the joint subjugation of the Javanese is explained in terms of the legitimate interest of individual Javanese persons in the plurality of the Javanese being free from subjugation. This view is not committed to the claim that the Javanese, individually, have a

10 Valentini objects to normativized conceptions of collective agency, according to which the tyrannical state does not count as a collective agent $(2015,324 \mathrm{n}$. 32). Those objections do not pertain to the plural interpretation. The plural view can acknowledge that the tyrannical state is a genuine collective agent, and it does not claim that the Javanese, as a people, constitute another collective agent that takes normative priority. Instead, the plural view does not tie the wrong of colonialism to corporate agency in the first place. 
legitimate interest in the tyrannical state being free from subjugation. Indeed, on the plural view, we can consistently hold that the Javanese individually have a legitimate interest both in the freedom of the plurality of Javanese people from being jointly subjugated by the Dutch, and in the overthrow of their tyrannical ruler. Valentini's arguments, then, do not show there to be any problem for the normatively individualist version of the plural interpretation.

\section{A Plural Interpretation of the Wrong of Colonialism?}

My aim in this paper is to show that a plural interpretation of the wrong of colonialism can avoid Valentini's dilemma. In doing so, I have not provided a complete pluralist theory of the wrong of colonialism. The main task for such a theory is to specify the conditions under which a plurality of persons jointly instantiates the property of being subjugated by a colonial ruler. Which properties would individual Javanese persons and individual Dutch persons need to have, and which relationships would need to exist between Javanese individuals, between Dutch individuals, and between Javanese and Dutch individuals, such that the plurality of the Javanese count as subjugated by the Dutch? My discussion of Valentini's arguments places certain constraints on viable answers. To avoid the over-ascription of the wrong of colonialism, the pluralist account should not hold that the lack of consent of a single Javanese person suffices for the plurality of the Javanese to count as subjugated by the Dutch. The same holds more generally for the realization of ideals of reciprocity and equality: our account should not hold that a failure to treat a single Javanese person on equal and reciprocal terms suffices for the Javanese to be jointly subjugated. Conversely, to avoid under-ascribing the wrong of colonialism, our account should not hold that the plurality of Javanese persons count as jointly subjugated only if each and every Javanese individual withholds consent to Dutch rule. Here again, the same is true for respecting norms of 
reciprocity and equality more generally. Beyond these constraints, however, my arguments here do not provide an account of the conditions under which a plurality counts as jointly subjugated.

In providing such an account, the plural interpretation will have to settle which pluralities matter when it comes to the wrong of colonialism. I will illustrate this issue by adding some historical detail to my main example. Before the full colonial rule of the island of Java by the Dutch government after 1830, Java was partially subject to colonial rule, and partially ruled by the kingdoms of Yogyakarta and Surakarta, each including a number of ethnically and culturally distinct groups. If we assume that the two kingdoms were the only available corporate agents capable of collective political agency, then the corporate interpretation will hold that the wrong of colonialism in this case is the subjugation of the kingdoms of Yogyakarta and Surakarta. The aggregative interpretation will say that the presence of the kingdoms is irrelevant: the wrong of colonialism simply is the subjugation of individual inhabitants of Java, regardless of their membership in one or another political organization. The plural interpretation will need an account of the relevant pluralities: which pluralities were subject to Dutch colonial rule on the island of Java? The Yogyakarta subjects and the Surakarta subjects; or the ethnically Javanese, the ethnically Sundanese, and the ethnically Madurese; or perhaps simply the plurality of all the inhabitants of Java? Ypi's account skips over this question by assuming that we know what the relevant political collectives are (2013, 162). It seems to me, however, that the plural interpretation gives rise to precisely the kind of question we should be able to answer if we are to understand the distinctive wrong of colonialism.

I should briefly consider a skeptical response to the aims of this paper. One might accept that pluralities can be loud, say, or heavy, but deny that pluralities can jointly instantiate properties such as being subjugated by a colonial ruler. Consequently, the plural account of the wrong of colonialism might avoid Valentini's dilemma, but it 
would nonetheless be a nonstarter. We should keep in mind here that I have used the term subjugation simply to summarize Ypi's account of the wrong of colonialism. Even if it seems that only individuals can be subjugated, we should ask whether pluralities can jointly fail to consent to the establishment of a political association, and whether pluralities can jointly fail to relate on equal and reciprocal terms to a colonizing power. I don't see reason for skepticism here. In fact, I believe that existing theories of shared intentionality provide some basis for optimism by providing us with accounts of how people can share intentions and act together without constituting a collective or corporate agent. According to Bratman, for example, we can share an intention by having the right kind of structure of interlocking intentions, subplans, and beliefs (2014, chapter 1-4); on Gilbert's view, we can do so by being jointly committed to do something together (2006, chapter 6). Although neither Gilbert nor Bratman explicitly commit themselves to a plural interpretation of shared intention, their views are quite naturally understood in those terms: a plurality of persons jointly realize the conditions for having a shared intention, they don't each do so, and they don't constitute a further agent which does. ${ }^{11}$ This is not to say that the kind of pluralities involved in colonization-the Javanese, say, or the Madurese-would normally satisfy Bratman's or Gilbert's conditions for shared intentionality. Nonetheless, it seems to me that if Gilbert, Bratman, and others are right that pluralities can jointly intend and act, then this provides a basis for optimism that pluralities may jointly consent or fail to consent to

\footnotetext{
${ }^{11}$ Pettit and List also hold that collections of individuals can jointly intend and act without constituting a group agent $(2011,33-4)$. Further, Pettit's republican account of democratic governance allows "the people considered as a plurality" $(2012,286)$ to govern themselves, where this is distinguished from the sense in which the people govern themselves as a single, corporate agent (2012, 286).
} 
rule, and that pluralities may be, or fail to be, provided with equal and reciprocal terms of political association.

This paper has been about how we are to understand the colonized, but the central idea of this paper may be of wider significance in moral and political philosophy. My arguments concern the wrong of colonialism in particular because the exchange between Ypi and Valentini makes vivid why it matters that we need not think of the wronged in either individual or corporate terms. The general idea that pluralities of persons can be wronged may, however, have application beyond the specific case of colonialism. It is not inconceivable, for example, that at least part of the wrong of certain discriminatory acts, certain forms of hate speech, or of genocide is best understood in plural terms.

\section{Acknowledgements}

This paper wouldn't exist if Rowan Mellor hadn't convinced me of the significance of plurals for a number of problems in moral and political philosophy. I'm also grateful to Laura Valentini, Avia Pasternak, and an anonymous referee for this journal for written comments, and to the UCL political theory cherry picking seminar for discussion.

\section{References}

Bratman, Michael. 2014. Shared Agency: A Planning Theory of Acting Together. Oxford: Oxford University Press.

Gilbert, Margaret. 2006. A Theory of Political Obligation: Membership, Commitment, and the Bonds of Society. Oxford: Oxford University Press.

Linnebo, Øystein. 2014. "Plural Quantification", The Stanford Encyclopedia of Philosophy (Fall 2014 Edition), Edward N. Zalta (ed.), URL $=<\underline{\text { https: / / plato.stanford.edu } /}$ archives / fall2014/entries/plural-quant/>. 
List, Christian and Philip Pettit. 2011. Group Agency: The Possibility, Design, and Status of Corporate Agents. Oxford: Oxford University Press.

Mellor, Rowan. 2017. What is Collective Responsibility? MPhil. Thesis, University College London.

Pettit, Philip. 2012. On the People's Terms. Cambridge : Cambridge University Press.

Rickless, M.C. 2001. A History of Modern Indonesia since c. 1200, Third Edition. Palgrave.

Smith, Thomas H. 2011. "Playing One's Part," Review of Philosophy and Psychology 2, no. $2,213-244$.

Valentini, Laura. 2015. "On the Distinctive Procedural Wrong of Colonialism," Philosophy and Public Affairs 43, no. 4, 312-331.

Ypi, Lea. 2013. “What's Wrong with Colonialism," Philosophy and Public Affairs 41, no. 2, 158-191. 